\title{
On the Development Dilemma of China's Art Market and the Reconstruction of Ecosystem
}

\author{
Shuo Wang*, Yang Song
}

Nankai University Binhai College, Tianjin, China

*Corresponding author

\begin{abstract}
Based on the deep ecological theory and value chain theory, this article starts from the perspective of the art market ecological environment, summarizes the problems in the art market production, circulation, consumption and other links, and conducts a targeted analysis of its supply chain and art trading industry chain. It believes that the lack of value system, upside down market structure, and capital orientation of art investment have led to an imbalance in the art ecology, and put forward the idea of building a "hive structure" ecosystem in the art market.
\end{abstract}

Keywords: Art market, Hive structure, Ecosystem, Art trading

\section{论我国艺术市场发展困境与生态系统的重建}

\author{
王硕 ${ }^{*}$ 宋扬
}

南开大学滨海学院, 天津, 中国

“通讯作者

中文摘要

本文基于深生态理论和价值链理论，从艺术市场生态环境的角度入手，总结了艺术市场生产、流通、 消费等环节存在的问题，并对其供应链和艺术交易产业链等进行了针对性分析，认为价值体系缺失、 市场结构倒挂以及艺术品投资的资本导向导致了艺术生态的失衡，并提出了建设艺术市场 “蜂巢结构” 生态系统的构想。

关键词: 艺术市场; 蜂巢结构; 生态系统; 艺术品交易

\section{1. 本文理论基础}

深生态学理论 (Deep Ecology Theory) 由挪威哲学 家纳斯 (Ame Naess) 提出, 是关乎现代环境伦理学的 一种创造性理论 ${ }^{[1]}$ 。该理论认为生态问题不能仅从技术 角度解决, 而要从哲学、伦理、政治、社会等方向去探 索人们的价值观、生活方式、经济活动、文化活动等与 人类所面临的环境危机之间的关系，从而保证人与人、 人与自然关系的协调发展。基于此雷毅（2012）认为生 物的自我实现就是不断扩大自我与他人、他物的认同过 程。在这个进程中最终会实现“生态中心主义”的结果 ${ }^{[2]}$ 。 在艺术市场中, 我们考虑更多的不是人与自然的关系, 而是要从深生态学的角度探讨人与人、人与行业、行业 与行业之间的相互协调。

价值链理论（Value Chain Theory）由美国著名管理 学专家迈克尔. 波特 (Michael Porter) 提出, 他认为企
业活动是一个集合, 由设计、生产、销售、输送和辅助 等部分组成, 指出价值链包括企业内在价值链、竞争者 价值链和行业价值链三部分, 其中行业价值链主要指企 业需要从整体行业所处环境出发, 从更高的角度审视供 应商、生产商、经销商的关系, 通过价值链来降低成本 ${ }^{[3]}$ 。

\section{2. 我国艺术市场交易现状}

从整体艺术市场交易来看, 中国市场经历了由鄚高 到回落的阶段。2011 年, 中国艺术品交易份额一度超过 美国, 成为全球最大艺术品市场, 但随即就在 2012 年 大幅回落, 再度被美国取代。2013 年虽小幅回升但依然 无法撼动美国地位, 在经历了县花一现式的辉煌之后体 现出前进无力的疲态, 当年中国继续保有全球艺术品交 易第二名头衔，占全球艺术品市场份额的 $24 \%$; 全球最 
大艺术品交易市场依然由美国把持，占总份额的 38\%； 第三位则是英国, 占有 $20 \%$ 的市场份额, 此种态势一直 保持至 2017 年，除美国持续领先之外，中国和英国交 替排名次席。2017 年全球艺术品市场交易总额 637 亿美 元，继两年下滑之后实现了交易额和交易量的回升, 其 中第一名美国市场份额为 $42 \%$, 中国 $21 \%$, 英国 $17 \%$ 。 从交易额来看, 2017 年中国市场成交额为 132 亿美元, 其中 $70 \%$ 来自拍卖。在拍卖引领成交额增长的同时, 不 难发现中国画廊行业当前发展依然缓慢。对于近年来整 体艺术市场发展趋势, 业内人士普遍认为在宏观经济进 入下行空间、中美贸易摩擦的前提下，“调整”依然是艺 术市场生态之中的关键词 ${ }^{[4]}$ 。甚至也有观点认为, 此种 持续多年的调整具有结构性特征, 如果不能解决中国艺 术市场文化影响力的问题, 那么调整前景将呈现“L”型 路线, 即无限期低迷发展 ${ }^{[5]}$ 。

\section{3. 艺术市场结构缺陷与问题归纳}

\section{1. 艺术市场的结构分析}

艺术市场的繁荣有赖于各类参与群体的集体觉醒, 转变传统急功近利的以资本和市场为导向的价值观念 为以生态为重、关心艺术市场整体环境的 “生态导向” 价值观, 是其中的决定影响因素。以下对艺术市场中的 供应链和产业链进行分析:

\subsection{1. 供应链分析}

供应链是一个流通的概念。供应链涉及产品提供给 用户的上下游活动, 以艺术市场供应链而言, 就是从艺 术品创作到销售再到最后被消费的阶段, 这其中, 我们 将中间最关键的销售平台即画廊和拍卖行视作核心环 节; 将艺术家及其经纪人视作供应方; 而将各类收藏家 和投资人视作供应链下游用户。分析可知现存艺术市场 供应链中虽然也存在着供应、经销、用户等层次, 但其 关系较为复杂, 作为供应商的艺术家, 既有可能直接同 核心经销商联系, 也有可能通过其经纪人与之交涉, 更 有一部分收藏家也在充当着中介的角色; 作为核心经销 商的画廊与拍卖行地位倒挂, 二者不是艺术家推介与艺 术品推广的合作分工，而是存在着相当大程度的竞争关 系; 作为用户, 既有资本运作为目的的投资者, 也有部 分收藏家作为最终用户。供应链体现了结构成员之间相 互依存关系, 这种关系应该是相互促进而不是相互掣 肘, 其整体运作效率非常重要, 对于供应链流畅程度要 求较高。

\subsection{2. 产业链分析}

产业链描述同一产业不同分工的企业群落之间的 内在联系, 其范围大于单一企业的供应链, 完整的产业
链应体现连贯的产业过程。艺术市场存在于整个艺术品 交易产业链之中, 对于这条利益链, 关键在于挖掘和强 化上游群落的存在价值, 只有这样中下游的交易和流通 领域才会有进一步发展空间。当前围绕我国艺术品市场 展开的产业链条非常不完善, 从上游的生产环节来看, 由于学术机构的缺失, 导致作品风格的散乱无章, 核心 生产力积弱难返; 业务服务方面, 保险、金融、仓储等 专业服务均有缺失, 其工作目前完全由经营群体自己承 担, 既不专业, 风险也高; 作为影响产业发展的重要信 息服务环节中的举足轻重的力量, 行业协会和研究机构 并没有发挥出应有的作用，游离于市场之外; 业务推广 乏力, 举措不多; 市场监管完全缺失; 投资收藏缺乏系 统规划与专业指导。所以说, 我国当前艺术品市场的产 业链条, 是一条不完整、不科学的 “残链”, 需要以深 生态理念为导引, 在兼顾盈利能力和生态空间的条件 下, 补足、延伸其产业链条, 实现行业突破发展。

\section{2. 艺术市场结构问题}

从艺术生态结构来看, 中国的艺术市场内部存在着 如下问题:

\subsection{1. 生产层次, 学术研究缺位, 价值体系缺 失}

部分艺术家，未能建立起符合中国本土精神的艺术 价值体系, 而是一味跟风西方标准, 由此获得资本青睐 （范伟民，2009）[6]。而西方资本占据中国艺术市场交 易份额越多, 西方价值观对艺术家价值判断的影响就越 深入, 最终导致一种唯市场马首是瞻、跟风创作的艺术 习惯，导致艺术市场虽然表面繁荣，但作品整体风格趋 同，格调有限。吉昆（2017）亦认为随着近几年图式化 风格的流行, 艺术正在大踏步向娱乐化方向迈进, 艺术 市场失去了严肃传统, 变得越来越趋同于时尚市场 ${ }^{[7]}$ 。

\subsection{2. 流通层次，两级市场倒挂，艺术精品枯 竭}

一方面, 作为二级市场的拍卖行殚精竭虑的想要提 高拍品拍卖价格，在征集拍品的过程中与各类艺术家有 着太多的交集。这种将二级市场触角深入生产领域, “订 单式生产” 的做法或许提升了拍卖行自身的重要性, 但 对于整个艺术市场而言却并非长久之计。艺术家长期稳 定的作品风格的实现和个人发展路径的规划离不开画 廊的塑造, 画廊自身市场积累、学术经验、社会资源等 对其进行包装与推介, 在此基础上逐渐建立起作者成熟 的艺术风格, 这显然是关心以最高效率实现产品增值的 拍卖行所无法胜任的, 当前由于画廊的缺位, 我国的拍 卖行不得不有意无意的充当着一次推介的角色, 长远来 看，这对艺术市场生态而言并无益处。另一方面，画廊 
本属于艺术品交易一级市场，但由于我国特殊市场环 境, 其生存要比拍卖行业恶劣的多, 在一二级市场市场 地位扭曲现实和国际知名画廊的联合挤压之下，国内一 些画廊放弃自身对艺术家发展的长期关注, 不再注意对 艺术家及其作品进行宣传、推广和包装, 渐渐沦为通过 倒买倒卖赚取差价的画店, 甚至成为不法商人和政客的 洗钱工具, 发展前途暗淡。

\subsection{3. 消费层次，资本运作导向，艺术修养欠} 缶九

一方面中国藏家在艺术消费偏好上, 与西方藏家有 着明显区别, 这种区别体现出一种“定向性”。中国藏家 出于情感的原因, 更倾向于中国艺术, $90 \%$ 的中国藏家 只收藏中国艺术作品, 而且其尤为青崃的是近现代书 画, 而对当代艺术显得兴趣不高。另一方面随着近年来 收藏机构等投资资本进入到市场之中，金融资本逐渐替 代传统收藏家成为了决定艺术市场的重要力量, 大部分 收藏者把自己定位成投资人而不是艺术家，资本的逐利 性导致其对艺术市场生态环境问题欠缺思考, 一旦经济 环境发生变化，金融资本的大量退潮将直接影响艺术市 场很难获得足够的发展驱动。针对这一点, 杨紫怡 （2017）曾提出艺术市场越来越受到金融领域的压力, 由宏观环境所带来的金融风险不可避免的将更多的影 响艺术领域 ${ }^{[8]}$ 。

\section{4. 艺术市场健康发展与生态系统的重建}

艺术市场问题的最终解决, 不能满足于独立层次的 修补, 更应该注重整体环境的重塑。艺术市场是一个完 整的生态环境, 围绕艺术市场存在着一个复杂的 “生态 圈”，维持这个系统之中各相关群落的良好、高效、有 序的发展, 是整个艺术市场良性运转的基础, 也是破解 当前我国艺术市场低迷运行的良药。生态观念指导下的 艺术市场应体现艺术反映自然、艺术融入社会, 社会反 哺艺术的和谐、共存、合作的关系。构建健康发展的艺 术市场, 必须明了一个前提, 即 “环境决定生存” , 有 什么样的生态环境, 就有什么样的市场特征。今天艺术 市场中所面临的大多数问题, 其实都能够从艺术生态的 失衡中找到答案, 低层次的修修补补, 已经无法完全解 决这种失衡所造成的恶果, 因此, 秉承 “环境决定生存” 的主旨, 依照深生态发展观, 重建一个群落与群落互洽、 群落与系统共生的生态系统成为了艺术界的重要责任。

在这个生态系统中, 艺术家、专业机构、学术机构、 交易市场、行业协会、各类服务组织、政府部门、金融 机构和互联网平台等都各司其职, 在自身职责范围内构 建着链条上的每一个模块, 以自身为中心营造 “生态微 环境” , 各模块通过利益链条相连, 其交汇的中心点在 于艺术品流通环节, 通过模块之间的相互支撑、紧密合 作、融会贯通来完成整体价值链条, 形成和谐的艺术氛 围，打造构造合理、结构牢固的艺术市场 “蜂巢式” 生
态系统。艺术市场 “蜂巢式” 生态系统实现了艺术生产 系统、业务系统、收藏系统、先导服务系统、后续服务 系统、信息系统和监管系统七大模块的协调统一，七个 模块构成三条相关链条, 所有链条都交集于业务系统这 个流通的中心环节。

\section{1. 生产系统}

以学术机构的研究课题为起点, 通过将艺术理论成 果、艺术前沿动态、艺术价值取向向艺术家传递，从而 实现包含了经纪人、艺术顾问、艺术展馆和策展人以及 收藏家在内的整个生产系统微循环，在此模块之中，艺 术家将不再单单扮演一个闭门造车或者跟风而动的创 造者，而是各类艺术理论的实践者和艺术观念的集大成 者, 有助于他们形成清晰的价值取向和独特的作品风 格。

\section{2. 业务系统}

调整了画廊与拍卖行的关系，解决了当前一二级市 场倒挂的问题。在对画廊与拍卖行业务整合的同时，增 添了艺术交易所这一新型交易平台作为补充交易形式。

\section{3. 收藏系统}

生态链的最终环节，也是整体生态循环的起始环 节。在 “蜂巢结构” 中，投资人、收藏家不是盲目的、 仅凭价值导向进行相关艺术品的消费，而是在艺术顾问 和投资顾问的协助下，从美学和市场角度同时考虑对艺 术品的投资收藏, 并通过参加学术峰会和增加国际交流 等方式构建交流机制, 提供更理性的艺术见解和国际化 收藏视野。藏品展示机制也鼓励收藏家和投资人将所保 存的艺术品面向公众开放展览, 在提升藏品美学价值的 同时，也起到扩散受众群体，激发更多民众艺术热情的 作用, 从而为艺术品创作与交流提供更加广阔的孕育温 床。

以上生产系统、业务系统和收藏系统构成艺术市场 生态系统的产业链, 促进艺术品价值的全过程转移。

\section{4. 先导服务系统}

先导服务系统提供具体艺术业务产生之间的鉴定 服务、咨询服务、金融服务等环节专业化服务。

\section{5. 后续服务系统}

后续服务系统提供艺术交易发生之后的保险服务、 仓储服务、物流服务等环节, 将专业工作交于专业人士 处理，理顺流通流程。 
以上先导服务系统、业务系统、后续服务系统构成 艺术市场生态系统的服务链, 通过引入专业化服务机构 提高整体市场交易流动性, 保证艺术品交易更加流畅。

\section{6. 信息系统}

信息系统解决了影响艺术品交易效率的信息问题， 主要包括负责提供理论支持的研究机构、由负责提供咨 询、组织、协调、协助工作的行业协会、负责对艺术作 品审美情趣、为价值体系提供意见的批评家形成, 承担 信息咨询和建议职能。

\section{7. 监管系统}

监管体系是现有艺术品交易的缺失环节, 监管可以 视作一种确保价值传递过程顺畅并能够将企业、行业、 公众和更广泛的宏观环境的反馈信息及时回馈产业链 中的机制, 它可以保持行业始终处于平衡发展的轨道之 中, 是构成功能链的重要组成部分。

以上信息系统、业务系统和监管系统构成了艺术市 场生态系统的功能链, 在此链条中, 建议体系、业务系 统和监管机制形成了一种信息共享、监督反馈、改良促 进的良性互动关系。

在以上七大系统模块和三条关系链条中, 每一个模 块都是一个良性循环的子系统, 每三个模块构成一个与 市场发展休戚相关的利益链条, 模块与模块之间相互依 存, 相互支撑, 所有外围模块的核心都指向业务流通系 统这一艺术品交易的最核心环节, 从而构成了一个完 整、健康的生态系统结构。

\section{5. 结论}

当前我国艺术市场的低迷固然是对近年来野蛮增 长的盘整, 却也不妨将其看做重塑艺术生态的绝好契 机。其实这种市场的高低起伏, 正是生态系统在自发的 进行结构调整, 业界要做的只不过是在最合适的时机, 做最关键的推动。而现在, 这一机遇已经到来。在深生 态理念的指引之下, 建立起一条围绕艺术市场形成的完 整产业链, 将所有产业链上相关群落都纳入到生态系统 中。在艺术市场的 “蜂巢式” 生态系统中业界、产界、 学界、商界、政界联手打造了一个紧密相连、互助合作、 互利共赢的产业环境, 在此环境中重生的艺术市场将换 发勃勃生机, 它将是艺术一一社会一一自然生态观的完 美展现。

\section{REFERENCES}

[1] A. Naess. Freedom, Emotion and Self-Subsistence: The Structure of a Central Part of Spinoza's Ethics. Universitetsforl, Oslo, 1975.
[2] Y. Lei. Deep Ecology: Interpretation and Integration. Shanghai Jiaotong University Press, Shanghai, 2012.

[3] M. Porter. Competitive Strategy. CITIC Press, Beijing, 2014.

[4] W. L. Wu. Indifferent and not calm-inventory of the 2019 Chinese art market ecology. J. Art market, 01(2020) 16-17.

[5] Y. Cao. The art market prospect may be a huge "L". Shanghai Securities News, 2015-12-21 (009).

[6] W. M. Fan. Thoughts on Chinese contemporary art and art market. J. Sculpture, 3(2009) 44-45.

[7] K. Ji. How to Keep Yourself Today in the Hot Art Market in China. J. Think Tank Era, 12(2017) $256-256+258$.

[8] Z. Y. Yang. Capital boosting the art market shouldn't be ride with lax reins. J. Faren Magazine, 08(2017) 84-85. 